\title{
Shortened duration of the annual Neocalanus plumchrus biomass peak in the Northeast Pacific
}

\author{
Sonia D. Batten ${ }^{1, *}$, David L. Mackas ${ }^{2}$ \\ ${ }^{1}$ Sir Alister Hardy Foundation for Ocean Science, c/o 4737 Vista View Cr., Nanaimo, British Columbia V9V 1N8, Canada \\ ${ }^{2}$ Fisheries and Oceans Canada, Institute of Ocean Sciences, PO Box 6000, Sidney, British Columbia V8L 4B2, Canada
}

\begin{abstract}
The calanoid copepod Neocalanus plumchrus (Marukawa) is a dominant member of the spring mesozooplankton in the subarctic North Pacific and Bering Sea. Previous studies have shown interdecadal and latitudinal variation in seasonal developmental timing, with peak biomass occurring earlier in years and places with warmer upper ocean temperatures. Because N. plumchrus normally has a single dominant annual cohort, its seasonal timing can be indexed from measurements of total population biomass or by following progressive changes in stage composition. Early studies empirically found that peak upper ocean biomass occurred when about half of the pre-dormant population had reached copepodite stage 5 (C5). However, more recent comparisons derived from recent Continuous Plankton Recorder (CPR) data now show peak biomass when a larger fraction (>80\%) of the population is at C5. CPR samples the surface 10 to $15 \mathrm{~m}$, but comparisons to depth-resolved BIONESS data show that this discrepancy is not an artefact of sampling depth. Other causes are either a prolongation of duration of pre-dormant $\mathrm{C} 5$ or a narrowing of the age range making up the annual cohort. We assessed changes in cohort width using a modification of Greve's cumulative percentile method, and found that average cohort widths in the Alaska Gyre were significantly narrower in 2000-2007 than in 1957-1965 (1968-1980 were intermediate). Net tow sampling of Strait of Georgia populations showed a similar significant narrowing of cohorts in the 2003-2005 sampling period. This study provides evidence that in addition to the shift to an earlier occurrence of peak biomass reported previously, the duration of the peak has also decreased in the last decade.
\end{abstract}

KEY WORDS: Neocalanus plumchrus $\cdot$ Copepod $\cdot$ Biomass $\cdot$ Continuous Plankton Recorder

\section{INTRODUCTION}

The calanoid copepod Neocalanus plumchrus (Marukawa) spends only a short fraction of the year in surface waters of the subarctic Pacific, completing its annual development cycle from early copepodite through to the sub-adult stage in about $3 \mathrm{mo}$, after which it migrates to deeper layers for prolonged seasonal dormancy, followed by maturation, mating, and spawning at depth. Recent data from Continuous Plankton Recorder (CPR) sampling, analyzed in this study, suggest that the surface abundance peak is now even narrower than shown in studies published before the CPR survey began in 2000 .
Miller et al. (1984, and revised by Miller \& Clemons 1988) detailed the annual life cycle of Neocalanus plumchrus at Ocean Station P (OSP) in the oceanic subarctic NE Pacific at $145^{\circ} \mathrm{W}, 50^{\circ} \mathrm{N}$. Maturation and spawning rates were at a maximum in the autumn, even though early copepodites were not present in surface waters until the following late winter/early spring. This contrasts with the coastal populations in the Strait of Georgia (a small but deep marginal sea lying between Vancouver Island and the coast of mainland North America) which mature in late winter, with a spawning peak in February (Fulton 1973). The duration of the surface biomass peak also varied between these 2 locations, being about $60 \mathrm{~d}$ at OSP 
(Miller 1993) but often $<40 \mathrm{~d}$ in the Strait of Georgia (Fulton 1973).

A more intensive sampling program allowed stage durations to be established for copepodite stages 1 to 4 (C1-C4; Miller 1993), and these duration estimates were used by Mackas et al. (1998), together with a time series of biomass data from OSP, to produce an index of the timing of peak biomass. Peak C2-C5 biomass was found empirically to occur when the proportion of C5 was between 35 and $65 \%$ of the total copepodite abundance; the midpoint, $50 \%$, was therefore used to estimate the date of peak biomass. This index allowed a precise date of peak biomass to be deduced from relatively infrequent sampling by linearly interpolating the stage composition between sampling dates. The index was subsequently used to show interdecadal variation in developmental timing including an advance in the peak biomass under warm ocean conditions (Mackas et al. 1998, 2007).

The CPR began sampling the NE Pacific in 2000 and has maintained 2 transects that sample the region between the outer coast of British Columbia, Canada, and OSP 6 to 9 times per year. The ' $50 \%$ C5' index was applied to the CPR stage composition data and showed a similar advance in the warmer years of 2004 to 2006 versus the cooler years of 2000 to 2002 (Mackas et al. 2007). However, estimates of biomass derived from the abundance data (as well as the raw abundance data themselves) suggested that the peak in biomass was occurring at a later date than given by the stagecomposition index (although the warm versus cool year advance was maintained). This study details the investigation into this discrepancy and possible implications.

\section{MATERIALS AND METHODS}

Zooplankton sampling. Continuous plankton recorder: The sampling and data analysis are as described by Mackas et al. (2007) but extended to include the subsequent additional sampling in 2005 and 2006. Two CPR transects intersect in the eastern Gulf of Alaska (Fig. 1). The 'North-South' route runs between Alaska (Prince William Sound in 2000 to 2003 or Cook Inlet in 2004 to 2006) and the west coast of the USA (Long Beach, California, in 2000 to 2003; Seattle, Washington, in 2004 to 2006) 5 to 6 times per year through spring and summer. The 'East-West' route runs be-

tween the Canada-USA border and Japan 3 times per year. The offshore study area shown in Fig. 1 has thus been sampled 6 to 9 times per year with about half of those samplings occurring in spring and early summer.

The CPR sampler and its deployment and sample processing methodologies (Richardson et al. 2006) are the same as have been used in the Atlantic since the 1940s. Briefly, a mechanical towed body (the CPR) is towed behind commercial ships at a depth of about $7 \mathrm{~m}$. Water and plankton enter a small hole at the front of the sampler and are progressively caught, rolled up, and preserved between 2 ribbons of silk gauze (mesh aperture $0.27 \mathrm{~mm}$ ). The movement of the gauze is mechanically driven by a propeller at the tail of the CPR and is proportional to distance traveled: each $10.16 \mathrm{~cm}$ panel of gauze filters a total of about $3.1 \mathrm{~m}^{3}$ of water and represents an average of about $18.5 \mathrm{~km}$ (10 nautical miles) along the transect. At the end of each trip, the cartridges containing the mesh are offloaded and shipped to a laboratory for sectioning and labeling of the gauze, followed by identification and enumeration of retained zooplankton by species and stage.

Copepodites of Neocalanus plumchrus are not routinely distinguished from their congener $N$. flemingeri in the CPR analysis, although C5 copepodites were counted in 2 size ranges from 2001 onwards (>4.2 mm and 3.4 to $3.9 \mathrm{~mm}$ ), the smaller of which are assumed to be $N$. flemingeri (Batten et al. 2003, Mackas et al. 2007). N. flemingeri completes its life cycle in surface waters earlier than $N$. plumchrus and is less dominant in the offshore NE Pacific (Miller \& Clemons 1988). In the following analyses, only the larger C5 copepodites 
were included, although for $\mathrm{C} 2, \mathrm{C} 3$, and $\mathrm{C} 4$, some $N$. flemingeri may also have been present, and for data from 2000, some N. flemingeri C5 may also have been present.

Conversion of abundance counts to biomass was achieved by multiplying the abundance of each stage by a stage specific dry weight and summing the products for each sample. Dry weights were calculated from published lengths and the calanoid copepod length:weight relationship from Planque \& Batten (2000), giving weights of C2: $21.3 \mu \mathrm{g}, \mathrm{C} 3: 57.2 \mu \mathrm{g}, \mathrm{C} 4$ : $161 \mu \mathrm{g}$, and C5: $488 \mu \mathrm{g}$. These dry weights are somewhat higher than those given by Mackas et al. (1998), but in fact the relative changes in total biomass between successive samplings is minimal if these values are adjusted.

The CPR samples the surface $\sim 10 \mathrm{~m}$ layer while the net samples used in previous studies of Neocalanus plumchrus life history sample much more of the water column (usually down to 150 to $250 \mathrm{~m}$ or more). Although $N$. plumchrus copepodites are generally believed to be near-surface day and night, we first needed to exclude the possibility that the CPR has sampled a biased stage composition. If different copepodite stages inhabit different strata, then applying the Mackas et al. (1998) index to CPR data could produce an erroneous date of peak biomass.

Net tows during the 1956-1980 OSP “weathership' time series: OSP was occupied semi-continuously as an offshore weather station from the 1950s to 1980, and the weatherships collected a variety of physical oceanographic time series (Tabata \& Peart 1985, Freeland 2007). The weatherships also collected frequent zooplankton samples: vertical net tows covering the upper $150 \mathrm{~m}$ throughout most of the time series (Fulton 1983, Waddell \& McKinnell 1995), plus weekly sampling to $2000 \mathrm{~m}$ in 1980 to 1981 (Miller et al. 1984, Miller \& Clemons 1988). The majority of the 0 to $150 \mathrm{~m}$ samples were analyzed only for total wet weight biomass, but dominant species (including combined Neocalanus plumchrus/flemingeri) and their later developmental stages were enumerated in 1971, 1973, and 1980 (Waddell \& McKinnell 1995). As noted above, Mackas et al. (1998) estimated seasonal timing of $N$. plumchrus during the weathership time series using a combination of the biomass (all years) and stage composition $(1971,1973,1980)$ indices, and concluded (based on those years of overlap) that peak biomass corresponded to a C5:total copepodites ratio between 35 and $65 \%$. In this paper, we applied an additional phenology index based on cumulative integration of the biomass time series (developed by Greve et al. 2001, 2005, and described below) to examine interannual variation in cohort width (i.e. the duration of the period of high biomass).
Depth-stratified sampling with multiple net systems: After the termination of the semi-continuous weathership time series, multiple-net zooplankton sampling systems (BIONESS [B], MOCNESS [M], and/or Tucker trawl [TT]) were deployed from intensive but shorter duration research programs in the study area in late spring of several years (Fig. 1): 1984 (B), 1987 (B\&M), 1988 (M), 1996 to 1997 (TT), and 2000 to 2004 (B) have provided samples of zooplankton abundance within discrete depth bands. Typical depth strata for these tows were: $0-10,10-25,25-50,50-75$, 75-100, 100-150, and 150-250 m per haul (for additional details, see Mackas et al. 1993, Miller 1993, Goldblatt et al. 1999). Although contemporaneous depth-stratified and CPR sampling was too limited for direct comparison, these data do enable us to compare the depth preferences of the different copepodite stages. B samples from May or June within the study area were used (Table 1), and only from the depth bands listed above. Separate densities of C2 to C5 (Neocalanus plumchrus plus $N$. flemingeri for C2 to C4) copepodites were calculated for each depth band, integrated over the $250 \mathrm{~m}$ sampling depth, and then the proportion of each stage occurring within each depth band was calculated for each year.

Analysis. Estimation of peak biomass: The estimation of the date of peak biomass from stage composition CPR data follows the methodology of Mackas et al. (1998). The proportion of the C2-C5 community present as C5 on each sampling date was calculated. Linear interpolation was used to deduce the date at which $50 \%$ of the population were at the C5 stage (since this date usually occurred between samplings).

Estimation of cohort width: Greve and colleagues have developed and applied an alternative method for indexing zooplankton seasonal phenology (examples in Greve et al. 2001, 2005 and Valdés et al. 2006) that relies on cumulative integration through each year of the bell-shaped curve of abundance versus date or biomass versus date. 'Start-of-season' is defined as the date at which the cumulative curve crosses a lower threshold (15th or 25th percentile), 'middle-of-season'

Table 1. Summary of BIONESS hauls in each year used in the analyses

\begin{tabular}{|ccc|}
\hline Year & Period & Number of hauls \\
\hline 1986 & 14-15 June & 5 \\
1987 & 6-9 June & 5 \\
1993 & 25 June & 2 \\
2000 & 18-22 June & 7 \\
2001 & 4-11 June & 10 \\
2002 & 5-6 May & 2 \\
2003 & 18-19 June & 2 \\
2004 & 27-31 May & 4 \\
\hline
\end{tabular}


as the date for the 50th percentile, and 'end-of-season' as the 75th or 85th percentile. For our purposes, the 'duration-of-season' estimate (number of days between the 25th and 75th percentiles) provides a useful index of cohort width.

Sampling at OSP was often very frequent (a few days apart) and a 3 point running median was used to smooth the time series. Bongo net sampling has also occurred in the adjacent Strait of Georgia (Fig. 1) sporadically over the last few decades with sufficient temporal resolution to calculate cohort width occurring in the years 1966-1968, 1976, 1996-1998, and 2003-2005 (Fulton 1973, Bornhold 2000, R. El-Sabaawi pers. comm.). Sampling occurred between 6 and 23 times per year (i.e. at least as frequently as the CPR sampling) and was typically a vertical net haul from $100 \mathrm{~m}$ to the surface.

Cohort widths were calculated for each year of biomass data from the Strait of Georgia, OSP weathership, and NE Pacific CPR time series as the number of days between the 25th and 75th percentile of the cumulative abundance (interpolating where necessary between successive samplings).
Model of population abundance, biomass, and stage composition versus cohort age composition: To examine the effects of varying cohort width and/or relative stage duration on the relationship between biomass-based and stage-composition-based timing indices, we reapplied a time-step spreadsheet model of growth, survival, and stage progression that was originally developed by Miller (1993) and subsequently applied by Mackas et al. $(1998,2007)$. Input parameters for the model are daily growth and survival rates versus copepodite stage, durations (days) of the 5 pre-dormant copepodite stages, and starting width of the copepodite cohort (SD in days of the bell-shaped abundance versus age-at-date curve). Outputs are total and stage-specific biomass and abundance versus date. Our original application (Mackas et al. 1998) had used a uniform weight-specific growth rate $(7.3 \%$ $\mathrm{d}^{-1}$ ), a mortality rate that declined from $13 \% \mathrm{~d}^{-1}$ at the start of $\mathrm{C} 1$ to $3 \% \mathrm{~d}^{-1}$ at mid-C5, stage durations from Miller (1993), and a Gaussian cohort with width parameter (SD) of $12 \mathrm{~d}$. Here we report the effects of altering 2 of these parameters: a narrowing of the cohort width (SD reduced from 12 to $4 \mathrm{~d}$ ), and increasing the pre-dormant duration of C5 from 25 to $35 \mathrm{~d}$.
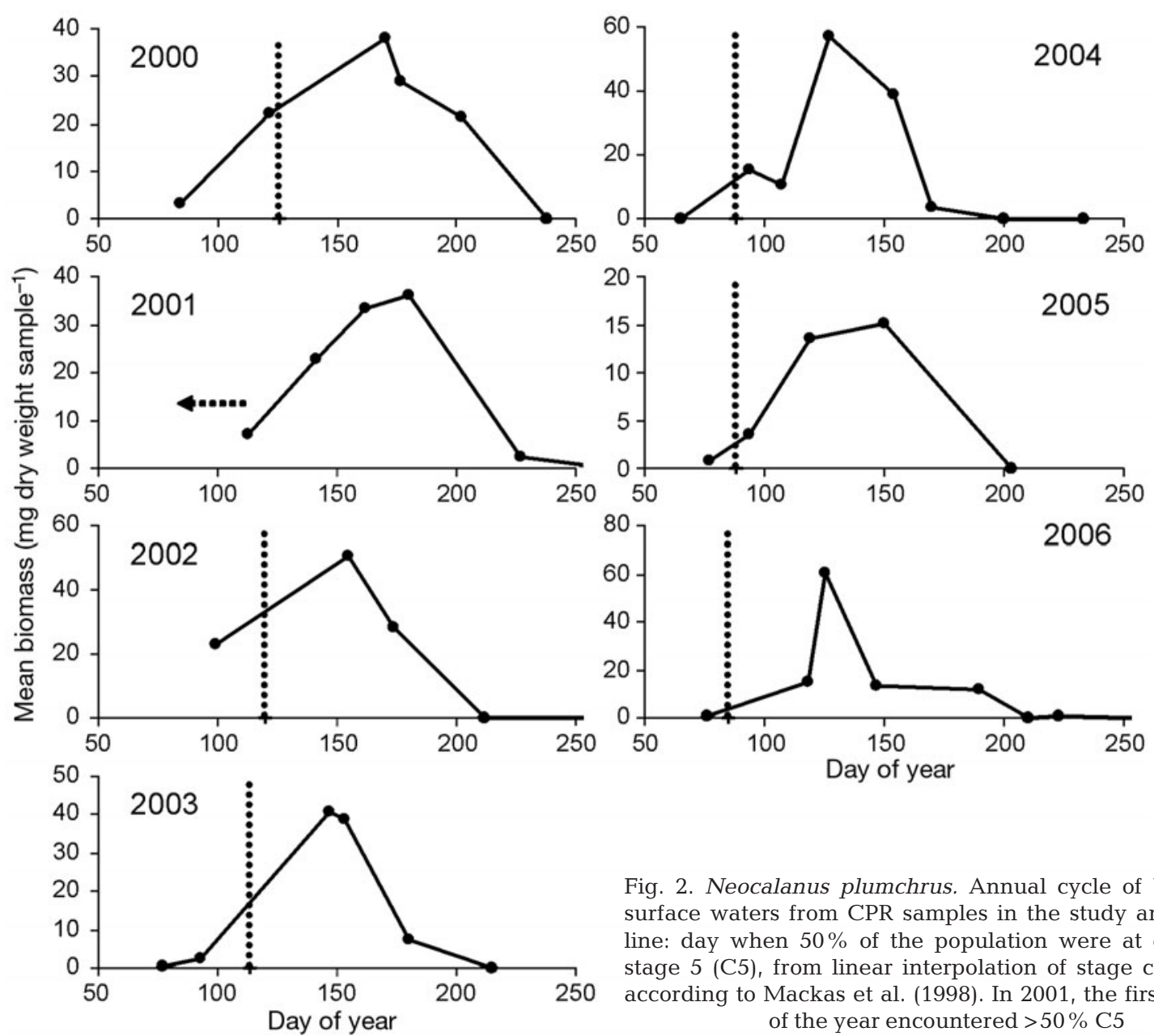

Fig. 2. Neocalanus plumchrus. Annual cycle of biomass in surface waters from CPR samples in the study area. Dotted line: day when $50 \%$ of the population were at copepodite stage 5 (C5), from linear interpolation of stage composition according to Mackas et al. (1998). In 2001, the first sampling of the year encountered $>50 \%$ C5 


\section{RESULTS}

The discrepancy in the estimates of peak biomass timing between the stage composition method (shown by the dashed lines) and the estimated sample biomass method is demonstrated in Fig. 2.

Because intervals between successive samplings of the study area by the CPR were between 6 and $67 \mathrm{~d}$ (mean of $29 \mathrm{~d}$ ), it is not possible to pinpoint the date of peak biomass from the sample biomass method (hence the appeal of the stage composition method); however, it is clear that in each year, the stage composition method gave a date far in advance of the maximum observed sample biomass. An alternative way of view-

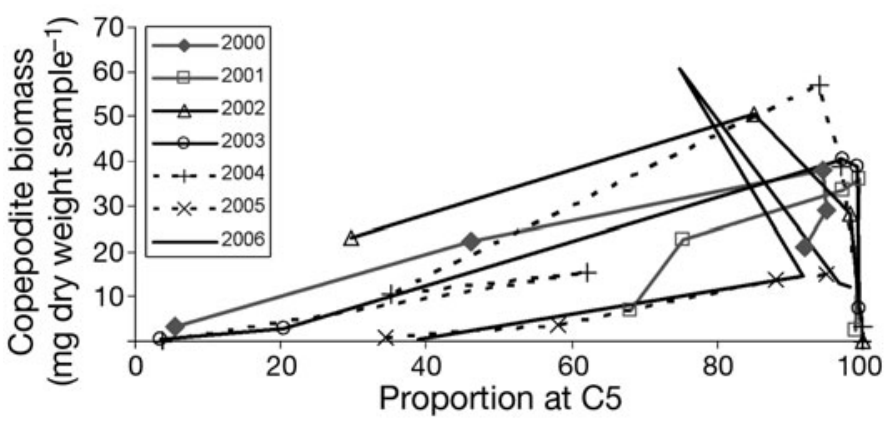

Fig. 3. Neocalanus plumchrus. Proportion of the C2-C5 community at $\mathrm{C} 5$ against the mean total copepodite biomass (mean dry weight in $\mathrm{mg}$ per CPR sample, $\sim 3 \mathrm{~m}^{3}$ ), from CPR data. If peak biomass were to occur when the population was around 50\% C5 (as in the Mackas et al. 1998 index), then bell-shaped curves with maxima centered near $50 \%$ would be expected. Instead, peak biomass occurs when the population is $>80 \% \mathrm{C} 5$ ing the CPR data is shown in Fig. 3, where the proportion of the community at pre-migrant C5 is plotted against the total biomass. Mackas et al. (1998) found the biomass peak to occur when C5 copepodites comprised between 35 and $65 \%$ of the C2-C5 abundance. The CPR data in Fig. 3 show that peak biomass was not reached until most ( $>80 \%$ ) of the population were at the pre-migrant stage in each year.

It was first necessary to establish whether there was a bias in the stage composition sampled by the CPR that could be responsible for this difference. Mean abundance of each copepodite stage in each depth band was calculated from the B data by averaging all years. Most of the copepodites in the water column at the time the B was sampling were C5, with the other stages making up only about $8 \%$ on average. In 1986 , 1993, and 2002, all copepodites were C5. Minor differences occurred in the proportions of each stage at each depth band (Fig. 4A) but the depth distribution of each stage (C2 to C5) was highly correlated with the depth distribution of each other stage ( $p<0.01$ in all cases). The depth band containing the highest number of copepodites was the 10 to 25 m layer, with at least $63 \%$ of each stage occurring in this stratum. The surface layer comprised $<13 \%$ of each stage on average. However, when means were calculated separately for each year, it became apparent that there were 2 distinct patterns, each occurring in multiple years. In 3 of the years (2000, 2001, and 2002) only about half of the copepodites were in the 10 to 25 m layer, with substantially more occurring in the surface $10 \mathrm{~m}$ layer. This was most obvious in the C5 (younger stages being
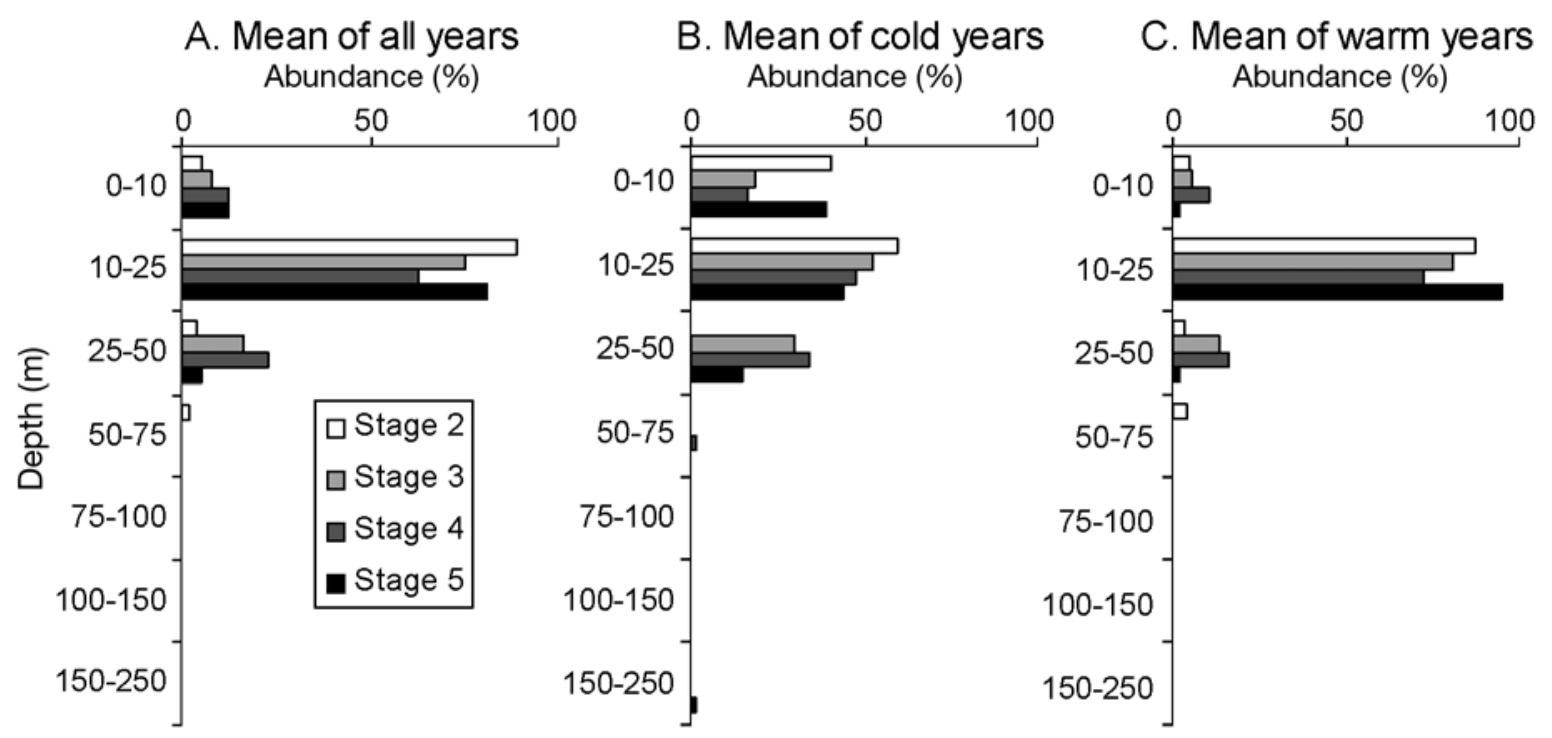

Fig. 4. Proportion of total water column abundance of each copepodite stage in each depth band from BIONESS data (locations shown in Fig. 1). (A) mean of all years, (B) mean for cold years (2000, 2001, and 2002), and (C) mean for warm years (1986, 1987, 1993, 2003, and 2004) 
scarce in late spring), and the mean proportion of $\mathrm{C} 5 \mathrm{in}$ the surface layer for these $3 \mathrm{yr}$ was $39 \%$ compared to $2 \%$ for the remaining years. Although we have not included environmental data from the B sample locations in this study, the years 2000, 2001, and 2002 were the coldest years of the sampling period according to data from the Amphitrite Point lighthouse on the southwest coast of Vancouver Island (Table 2, data available at: www-sci.pac.dfo-mpo.gc.ca/osap/data/ lighthouse/amphitrt.txt). We have thus designated 2 groups of years, warm $(1986,1987,1993,2003,2004)$ and cold $(2000,2001,2002)$, and show the depth distributions separately Fig. 4B,C. When the depth distributions of each copepodite stage were compared to the distributions of the other stages ( $\mathrm{C} 2$ to $\mathrm{C} 5$ ) within each group of warm or cold years, they were also significantly correlated ( $\mathrm{p}<0.01$ in most cases), the only exception being $\mathrm{C} 2$ versus $\mathrm{C} 4$ in cold years, where $\mathrm{p}=0.07$.

Notwithstanding the change in distribution of total abundance versus depth between warm and cold years, these analyses show that the fraction of the total

Table 2. Mean annual sea surface temperature (SST) from Amphitrite Point lighthouse for the years in which BIONESS data are available

\begin{tabular}{|lc|}
\hline Year & Mean annual SST $\left({ }^{\circ} \mathrm{C}\right)$ \\
\hline 1986 & 10.575 \\
1987 & 10.925 \\
1993 & 10.592 \\
2000 & 10.183 \\
2001 & 9.875 \\
2002 & 10.233 \\
2003 & 10.750 \\
2004 & 10.958 \\
\hline
\end{tabular}

contributed by each developmental stage is approximately homogeneous across all upper depth strata. The CPR samples at about $7 \mathrm{~m}$, and we cannot know with any certainty the degree of mixing behind the fast-moving, large vessels used to tow it, but it is likely that the samples contain plankton from well-mixed surface 10-15 m waters, perhaps deeper. Although the CPR will only be sampling a fraction of the total water column copepodites, it should be sampling each stage equally efficiently, and there is likely no bias caused by sampling to account for the discrepancy in peak biomass timing estimates.

Three time series of cohort width from OSP, the Strait of Georgia, and the CPR data in Fig. 1 are compared in Fig. 5; note that periods of overlap are minimal. The Strait of Georgia populations have a narrower cohort than the oceanic populations, which would be expected from the shorter duration of biomass described there by Fulton (1973) and compared by Miller (1993).

\section{DISCUSSION}

As high-frequency sampling of Neocalanus plumchrus in the NE Pacific is rare, and oceanic sampling is even less common, the CPR program has provided the greatest temporal resolution for this area (approximately monthly) since its inception in 2000. However, even this is inadequate for determining peak biomass timing without extrapolation. A few detailed surveys occurred prior to 2000, although in many cases separate stages were not counted. Two studies that do offer the opportunity to examine whether peak biomass has been found to occur when C5 copepodites comprise $\sim 50 \%$ of the population are TT data from May 1996

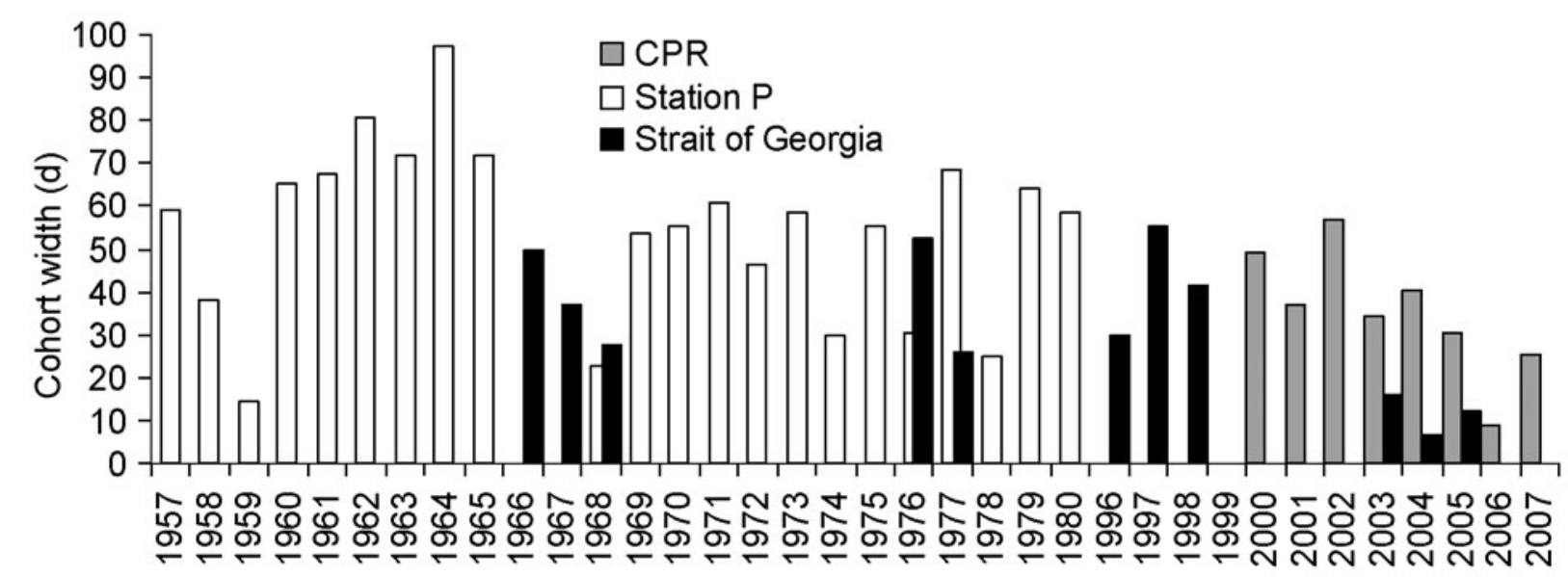

Fig 5. Neocalanus plumchrus. Index of cohort width in populations in the Strait of Georgia (from bongo net samples) and the oceanic NE Pacific (Ocean Station P net data, 1957 to 1980, and CPR data, 2000 to 2007, from the region shown in Fig. 1). No sampling occurred between 1981 and 1995 
(Goldblatt et al. 1999) and SUPER Program data from May 1988 (Miller 1993), although the timing of this latter survey was such that only $N$. flemingeri copepodites were sufficiently abundant. TTs also took place in June 1997, but by this later time, C5 copepodites already made up more than $50 \%$ of the population, as did N. flemingeri copepodites in both years. The 1988 $N$. flemingeri data and the $1996 \mathrm{~N}$. plumchrus data are shown in Fig. 6 and support the idea that peak biomass occurs when C5 copepodites make up approximately half of the population, since both graphs have a peak at about $60 \% \mathrm{C} 5$, within the range suggested by Mackas et al. (1998) of 35 to $65 \%$. They also both show a decline in total abundance as the population approaches $100 \%$ C5, expected if older C5 are migrating out of the surface layer to enter dormancy, but not evident in the CPR data in Fig. 3 (a conversion of these abundance data to biomass in the same manner as the CPR data in Fig. 3 did not change the shape of the graphs in Fig. 6). Although N. flemingeri is a different species with somewhat different behaviors to N. plumchrus, we have included the data in Fig. 6 for 2 reasons: (1) because so few suitable data exist for comparison, and (2) because $N$. flemingeri diapauses as an adult, we might expect the peak in $N$. flemingeri biomass to occur farther to the right of the graph than for $N$. plumchrus, i.e. when a higher proportion of the population is at C5, yet it does not. The fact that it is comparable to the $N$. plumchrus TT data reinforces the past utility of the $50 \%$ C5 peak biomass index, while suggesting that the post-2000 CPR data show something quite different.

Figs. 2 \& 3 suggest that the peak in biomass of Neocalanus plumchrus in the subarctic NE Pacific is now occurring when the population is mostly at the premigrant stage. This seems to have been true in each year since the CPR survey began in 2000 . We suggest that this must indicate a recent change in developmental chronology, compared to the period prior to 1998 , since a depth-dependent sampling bias is unlikely. One possible change could be that $\mathrm{C} 5$ are taking longer to store the lipid necessary for them to successfully diapause. If the pre-dormant duration of C5 has increased to provide additional time for lipid accumulation, our model (Fig. 7B) shows that this change causes an increase in the overall fractional abundance of $\mathrm{C} 5$, and also shifts the stage ratio at the date of peak biomass to a higher percentage of C5 (more similar to the graphs in Fig. 3). However, this explanation would also imply a prolongation of the total developmental sequence, such that significant numbers of $\mathrm{C} 5$ would continue to be caught later in the year, or over a longer period. This has not been seen from CPR data collected through the summer. The graphs in Fig. 2 suggest instead that the decline in numbers has become more rapid, with few individuals found after mid-June. This contrasts with OSP data from the 1970's when peak biomass often did not occur until July (Mackas et al. 2007).

An alternative explanation is that the cohort width has narrowed. Spawning occurs over an extended period beginning in the autumn (Miller et al. 1984, Miller \& Clemons 1988), but nauplii presumably only develop and migrate to the surface when conditions are suitable, i.e. in early spring. Mackas et al. (1998) concluded that differential survival of early versus late-arriving copepodites was responsible for the earlier peak in biomass in warm conditions. If the correct conditions for advancement occur for a shorter period of time, then the cohort will be more synchronized. Increased synchronization (a narrower cohort) will also strongly push the timing of peak biomass to a higher percentage of C5 (Fig. 7C). In the extreme case of complete synchronization of the cohort (all individuals exactly the same age in days), the peak biomass will occur when the entire population is at the C5 stage, and very close to the date when all individuals simultaneously enter diapause.
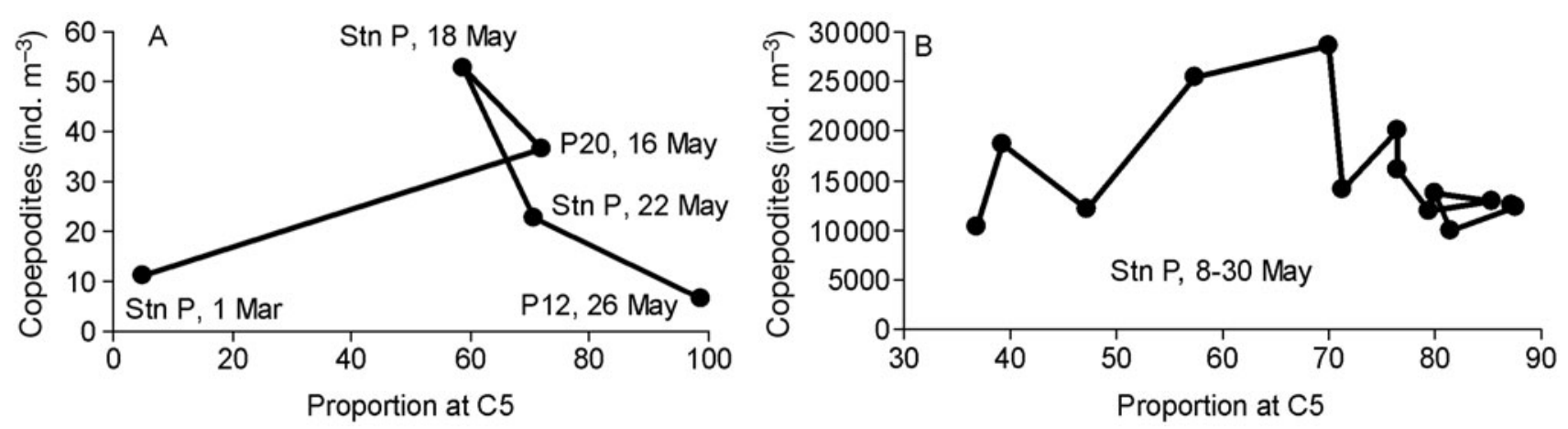

Fig 6. Neocalanus plumchrus and N. flemingeri. (A) Proportion of the N. plumchrus C2-C5 community at C5 against the mean C2-C5 density (to $150 \mathrm{~m}$ ) of copepodites collected by Tucker trawls in 1996. Station name (Ocean Station P, P20, or P12, see Fig. 1 for location) and date of sampling are shown alongside each data point. (B) N. flemingeri data from Ocean Station P, May 1988 


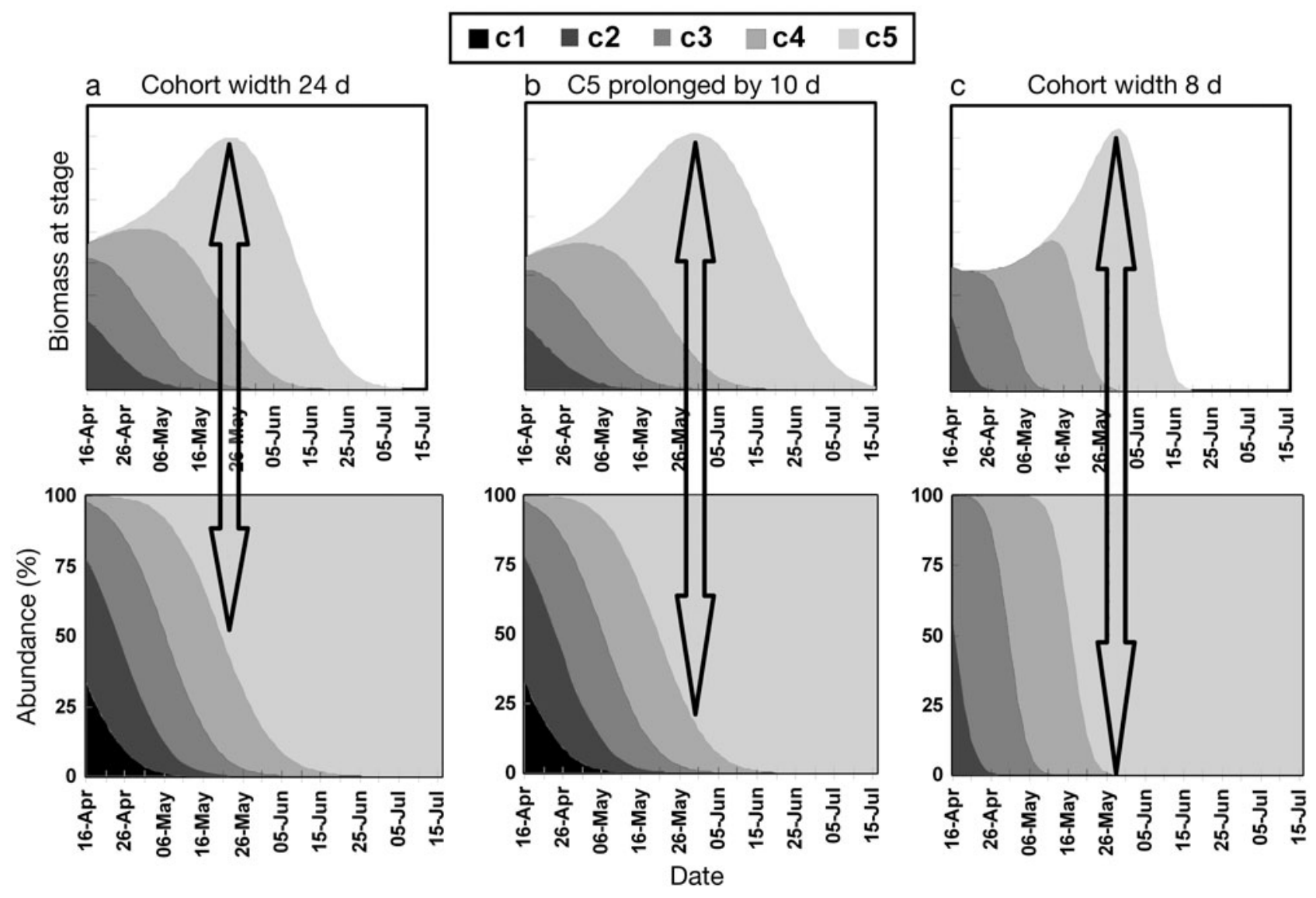

Fig 7. Model output showing stage-composition of total upper-ocean population biomass (top) and of percentage numeric abundance (bottom) vs. sampling date. (a) Base model as used in Mackas et al. (1998), biomass maximum occurs at about 50\% C5; (b) Persistence/prolongation of the pre-dormant duration of C5 (to allow accumulation of sufficient lipid to support subsequent dormancy), biomass maximum occurs at about $80 \%$ C5; (c) Narrowing of the overall cohort age structure by a factor of 3 (due to a narrower spawning or survival/developmental window), biomass maximum occurs at nearly $100 \%$ C5. Recent CPR time series are most similar to the pattern shown in (C)

All cohort widths post-2000 in the Strait of Georgia were narrower than the narrowest cohort there pre2000, lending some support to the idea that cohort width in this region has also narrowed since 2000 (Fig. 5). An analysis of variance (ANOVA) of the cohort widths found in 3 time periods (1966-1977, 1996-1998, and 2003-2005) shows that the cohort widths are significantly narrower $(F=8.28, \mathrm{p}<0.05)$ between the latter time period and both previous periods. The narrowest cohort in the oceanic NE Pacific was also found post-2000, in 2006 CPR data, although narrow cohorts also occurred at OSP in 1959, 1968, and 1978 (Fig. 5). The widest cohorts occurred in OSP data, and in fact 12 of the 21 years of OSP data had wider cohorts than the widest cohort in the CPR data (2002). We can consider the CPR data to be a continuation of the OSP time series, with the caveats that the CPR also sampled east of OSP (Fig. 1), and the OSP data were collected much more frequently. The time series can then be divided into 3 time periods, 1957-1965, 1968-1980, and
2000-2007. An ANOVA of cohort widths in each period shows that the most recent time period has significantly shorter cohorts than the earliest time period $(F=4.71, \mathrm{p}<0.02)$ but that adjacent time periods are not significantly different. The method of data collection and its frequency have changed in the Strait of Georgia time series. Prior to 2000, Neocalanus plumchrus biomass was calculated by converting from total zooplankton biomass (R. El-Sabaawi pers. comm.), whereas post-2000, N. plumchrus has been counted separately. It is not clear whether this would lead to a change in the cohort width, but the result remains somewhat speculative.

Thus, although the lack of consistently collected and fully comparable data means that the results must be treated with some caution, the evidence suggests that spring cohorts of Neocalanus plumchrus in both the Strait of Georgia and the oceanic NE Pacific have narrowed over the preceding decades and are now at their narrowest. 
The mechanism behind the advancement of peak biomass in warm years was considered by Mackas et al. (1998). The timing of the onset of thermal stratification was consistent with the earlier peak in biomass in the coastal Strait of Georgia populations compared to those at OSP, but no significant relationship was found between 3 indices of thermal stratification timing and the interannual variability in developmental timing. We have also considered temperature indices in relation to cohort narrowing. Mean monthly sea surface temperature is available from Amphitrite Point lighthouse, and winter (December to February), spring (March to May), and annual mean temperatures were correlated with the cohort width time series. In all cases, the correlations were negative (warmer temperatures were correlated with narrower cohorts), but only significantly so for the CPR time series and mean annual temperature of the previous year. Similarly, mean annual values of the Pacific Decadal Oscillation index were also negatively correlated with the time series, but only significantly so for the combined CPR and OSP, NE Pacific time series. It is likely that temperature is having some effect on both the timing of the peak biomass and the width of the cohort, but whether this is supplemented by other mechanisms or is in fact a proxy for another mechanism is not yet resolved.

There was also insufficient evidence to show whether the microzooplankton prey that make up the bulk of the Neocalanus diet at OSP (Gifford 1993) were even partially responsible for the advancement of peak biomass. Modeling results indicated that the copepods were more likely to influence the dynamics of their prey than vice versa. Dagg et al. (2006) also showed that mesoscale variations in food environment did not affect the final size before diapause of $N$. plumchrus and N. flemingeri in shelf waters of the Gulf of Alaska. Populations of $N$. plumchrus in the western Pacific have shown interdecadal variability in developmental timing of a similar magnitude. However, since the 1970s the pre-dormant surface-layer populations in the NW Pacific have not reached 50\% C5, suggesting that the cohort width may be increasing in the NW Pacific rather than narrowing (Chiba et al. 2006, K. Tadokoro unpubl. data). A significant correlation between phosphate concentrations and timing of peak biomass of C5 was found, suggesting that high nutrient conditions may prolong the period when suitable prey was available. It is possible that declining nutrient concentrations or other factors that limit prey availability are operating in the NE Pacific.

Whatever the cause, the results of our study suggest that not only is the period of plenty for Neocalanus predators occurring earlier in the year, but it is getting narrower. This has severe implications for the trophic functioning of the NE Pacific if the cause persists.
Acknowledgements. This work was funded by the North Pacific Research Board (projects R0302, 536, and 601) and the Exxon Valdez Oil Spill Trustee Council (projects 020624, 030624, 040624, and 070624). We are grateful to the officers and crews of the 'Polar Alaska,' 'Horizon Kodiak,' and the 'Skaubryn' and to Polar, Horizon and Seaboard International for their voluntary participation in the CPR survey. We are also grateful to R. El-Sabaawi for making available the Strait of Georgia data. This paper was presented at the Topic Session on 'Phenology and climate change in the North Pacific: implications of variability in the timing of zooplankton production to fish, seabirds, marine mammals and fisheries (humans)' on 2 November 2007 at the 16th Annual Meeting of PICES in Victoria, Canada. This is North Pacific Research Board publication no. 211.

\section{LITERATURE CITED}

Batten SD, Welch DW, Jonas T (2003) Latitudinal differences in the duration of development of Neocalanus plumchrus copepodites. Fish Oceanogr 12:201-208

Bornhold EA (2000) Interannual and interdecadal patterns in timing and abundance of phytoplankton and zooplankton in the central Strait of Georgia, with special reference to Neocalanus plumchrus. MSc thesis, University of British Columbia, Vancouver

Chiba S, Tadokoro K, Sugisaki H, Saino T (2006) Effects of decadal climate change on zooplankton over the last 50 years in the western North Pacific. Glob Change Biol 12:907-920

> Dagg MJ, Liu H, Thomas AC (2006) Effects of mesoscale phytoplankton variability on the copepods Neocalanus flemingeri and N. plumchrus in the coastal Gulf of Alaska. Deep Sea Res I 53:321-332

> Freeland H (2007) A short history of Ocean Station Papa and Line P. Prog Oceanogr 75:120-125

Fulton J (1973) Some aspects of the life history of Calanus plumchrus in the Strait of Georgia. J Fish Res Board Can 30:811-815

Fulton JD (1983) Seasonal and annual variation in net zooplankton at Ocean Station P, 1956-1980. Can Data Rep Fish Aquat Sci 374

Gifford DJ (1993) Protozoa in the diets of Neocalanus spp. in the oceanic subarctic Pacific Ocean. Prog Oceanogr 32: 223-237

Goldblatt RH, Mackas DL, Lewis AG (1999) Mesozooplankton community characteristics in the NE subarctic Pacific. Deep Sea Res II 46:2619-2644

Greve W, Lange U, Reiners F, Nast J (2001) Predicting the seasonality of North Sea zooplankton. In: Kroncke I, Turkay M, Sundermann J (eds) Burning issues of North Sea ecology. Proc 14th Int Senckenberg Conf 31:263-268

Greve W, Prinage S, Zidowitz H, Nast J, Reiners F (2005) On the phenology of North Sea ichthyoplankton. ICES J Mar Sci 62:1216-1223

> Mackas DL, Sefton H, Miller CB, Raich A (1993) Vertical habitat partitioning by large calanoid copepods in the oceanic subarctic Pacific in spring. Prog Oceanogr 32:259-294

Mackas DL, Goldblatt R, Lewis AG (1998) Interdecadal variation in development timing of Neocalanus plumchrus populations at Ocean Station P in the subarctic North Pacific. Can J Fish Aquat Sci 55:1878-1893

> Mackas DL, Batten SD, Trudel M (2007) Effects on zooplankton of a warming ocean: recent evidence from the Northeast Pacific. Prog Oceanogr 75:223-252

Miller CB (1993) Development of large copepods during 
spring in the Gulf of Alaska. Prog Oceanogr 32:295-317

Miller CB, Clemons M (1988) Revised life history analysis for large grazing copepods in the subarctic Pacific Ocean. Prog Oceanogr 20:293-313

Miller CB, Frost BW, Batchelder HP, Clemons MJ, Conway RE (1984) Life histories of large, grazing copepods in a subarctic ocean gyre: Neocalanus plumchrus, Neocalanus cristatus, and Eucalanus bungii in the Northeast Pacific. Prog Oceanogr 13:201-243

Planque B, Batten SD (2000) Calanus finmarchicus and the North Atlantic planktonic ecosystem. The year of Calanus in the context of inter-decadal changes. ICES J Mar Sci $57: 1528-1535$

Submitted: October 22, 2008; Accepted: April 2, 2009
Richardson AJ, Walne AW, John AWGJ, Jonas TD and others (2006) Using continuous plankton recorder data. Prog Oceanogr 68:27-74

Tabata S, Peart JL (1985) Statistics of oceanographic data based on hydrographic/CTD casts made at Ocean Station P during August 1956 through June 1981. Can Data Rep Hydrogr Ocean Sci 31

Valdés L, O'Brien T, López-Urrutia A (eds) (2006) Zooplankton monitoring results in the ICES area. summary status report 2004/2005. ICES Coop Res Rep 281

Waddell BJ, McKinnell S (1995) Ocean Station 'Papa' detailed zooplankton data: 1956-1980. Can Tech Rep Fish Aquat Sci 2056

Proofs received from author(s): June 24, 2009 